\title{
Does normal developmental expression of psychosis combine with environmental risk to cause persistence of psychosis? A psychosis proneness-persistence model
}

\author{
AUDREY COUGNARD ${ }^{1}$, MACHTELD MARCELIS ${ }^{2}$, INEZ MYIN-GERMEYS ${ }^{2}$, \\ RON DE GRAAF ${ }^{3}$, WILMA VOLLEBERGH ${ }^{3}$, LYDIA KRABBENDAM ${ }^{2}$, \\ ROSELIND LIEB ${ }^{4}$, HANS-ULRICH WITTCHEN ${ }^{4,5}$, CÉCILE HENQUET ${ }^{2}$, \\ JANNEKE SPAUWEN ${ }^{2}$ AND JIM VAN OS ${ }^{2,6 *}$ \\ ${ }^{1}$ INSERM U 657, University Victor Segalen Bordeaux 2, IFR99 of Public Health, Bordeaux, France; \\ ${ }^{2}$ Department of Psychiatry and Neuropsychology, South Limburg Mental Health Research and Teaching \\ Network, EURON, Maastricht University, Maastricht, The Netherlands $;{ }^{3}$ Netherlands Institute of Mental \\ Health and Addiction (Trimbos Institute), Utrecht, The Netherlands $;{ }^{4}$ Max Planck Institute of Psychiatry, \\ Clinical Psychology and Epidemiology Unit, Munich, Germany; ${ }^{5}$ Institute of Clinical Psychology and \\ Psychotherapy, Technical University Dresden, Dresden, Germany; ${ }^{6}$ Division of Psychological Medicine, \\ Institute of Psychiatry, London, UK
}

\begin{abstract}
Background. Research suggests that low-grade psychotic experiences in the general population are a common but transitory developmental phenomenon. Using two independent general population samples, the hypothesis was examined that common, non-clinical developmental expression of psychosis may become abnormally persistent when synergistically combined with developmental exposures that may impact on behavioural and neurotransmitter sensitization such as cannabis, trauma and urbanicity.
\end{abstract}

Method. The amount of synergism was estimated from the additive statistical interaction between baseline cannabis use, childhood trauma and urbanicity on the one hand, and baseline psychotic experiences on the other, in predicting 3-year follow-up psychotic experiences, using data from two large, longitudinal, random population samples from the Netherlands [The Netherlands Mental Health Survey and Incidence Study (NEMESIS)] and Germany [The Early Developmental Stages of Psychopathology (EDSP) study].

Results. The 3-year persistence rates of psychotic experiences were low at $26 \%$ in NEMESIS and $31 \%$ in EDSP. However, persistence rates were progressively higher with greater baseline number of environmental exposures in predicting follow-up psychotic experiences $\left(\chi^{2}=6 \cdot 9, \mathrm{df}=1\right.$, $p=0.009$ in NEMESIS and $\chi^{2}=4 \cdot 2, \mathrm{df}=1, p=0.04$ in EDSP). Between $21 \%$ and $83 \%$ (NEMESIS) and $29 \%$ and $51 \%$ (EDSP) of the subjects exposed to both environmental exposures and psychotic experiences at baseline had persistence of psychotic experiences at follow-up because of the synergistic action of the two factors.

Conclusion. The findings suggest that environmental risks for psychosis act additively, and that the level of environmental risk combines synergistically with non-clinical developmental expression of psychosis to cause abnormal persistence and, eventually, need for care.

\footnotetext{
* Address for correspondence: Professor Jim Van Os, Department of Psychiatry and Neuropsychology, Maastricht University, PO Box 616 (DRT 10), 6200 MD Maastricht, The Netherlands.
}

(Email: j.vanos@sp.unimaas.nl) 


\section{INTRODUCTION}

Recent lines of evidence suggest an interactive developmental model of psychosis (Cunningham Owens \& Johnstone, 2006). First, the expression of psychosis, whether it be psychotic disorders (prevalence $1 \%$ ), isolated psychotic symptoms (prevalence around $5 \%$ ) or broadly defined psychotic experiences (prevalence around 15\%) is much more common in young people and declines with age (Verdoux et al. 1998; Peters et al. 1999; Van Os et al. 2000; Johns \& Van Os, 2001; Myin-Germeys et al. 2003). Second, follow-up studies of young people with expression of psychosis at the subclinical level reveal that the great majority do not display psychosis at any level at follow-up (Hanssen et al. 2005). Third, the expression of psychosis at the subclinical or 'schizotypal' level clusters in families and is influenced in part by genetic factors (Linney et al. 2003; Hanssen et al. 2006). Finally, the generally good (because the symptoms are only transitory) outcome of subclinical psychotic experiences can be modified to poorer outcomes of persistence and clinical need for care if subjects are exposed to additional (proxy) environmental risk factors. Examples of these are trauma (Spauwen et al. 2006b), cannabis (Van Os et al. 2002; Henquet et al. 2005) and urbanicity (Van Os et al. 2003, 2004; Spauwen et al. 2004, 2006a).

The above findings suggest a model of psychosis that considers genetic background factors impacting on a broadly distributed and transitory population expression of psychosis during development, poor prognosis of which, in terms of persistence and clinical need, is predicted by environmental exposures interacting with genetic risk. In other words, transitory developmental expression of psychosis may become abnormally persistent and clinically relevant depending on the degree of environmental risk the person is additionally exposed to (Fig. 1). In the current paper, this model was tested in two separate samples, using measures of environmental risk combining several likely environmental exposures. In addition, recent statistical models of interaction (Darroch, 1997; Van Os \& Sham, 2003) allow for estimation of the amount of synergy between environmental risks and developmental expression of psychosis, as an indication of the morbidity

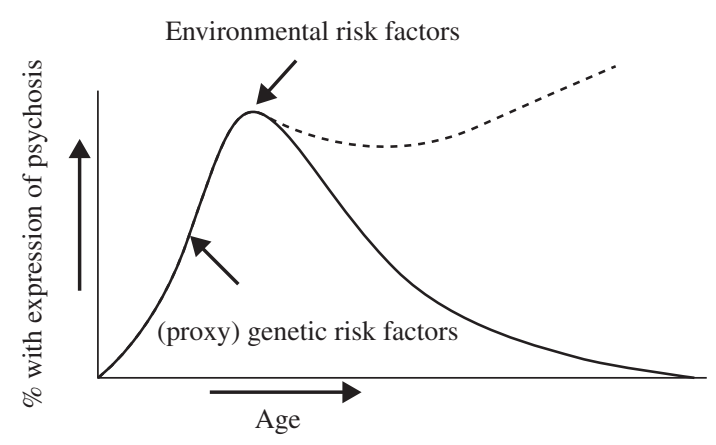

FIG. 1. Development of psychotic disorder: abnormal persistence (- - ) of developmental expression of psychosis.

specifically caused by the combination of the two factors.

\section{METHOD}

\section{Sample}

The Netherlands Mental Health Survey and Incidence Study (NEMESIS)

NEMESIS is a study of the prevalence, incidence, course and consequences of psychiatric disorders in the Dutch general population. The overall design of the study is prospective (3 years), consisting of a T0 baseline survey in 1996, and two follow-up surveys at T1 (assessing the period between T0 and T1) in 1997, and at T2 (assessing the period between T1 and T2) in 1999. A comprehensive description of the project objectives, sample procedure, response, diagnostic instruments, quality control procedures and analyses is provided in previous publications (Bijl et al. 1998a,b). NEMESIS is based on a multistage, stratified, random sampling procedure, in 90 municipalities. A sample of private households within each municipality and members with the most recent birthday within each household were selected (Bijl et al. 1998a,b). Subjects were aged 18-64 years and sufficiently fluent in Dutch to be interviewed. Individuals living in institutions were not eligible for interview. A total of 7076 individuals provided informed consent and were interviewed at $\mathrm{T} 0$, representing a response rate of $69 \cdot 7 \%$. Previous analyses have shown that psychopathology had only weak effects on attrition rate over the follow-up periods 
and was mainly related to failure to locate and morbidity/mortality rather than refusal (de Graaf et al. 2000).

\section{The Early Developmental Stages of the Psychopathology (EDSP) study}

The EDSP study (Lieb et al. 2000) collected data on the prevalence, incidence, risk factors, co-morbidity and course of mental disorders in a random, representative population sample of adolescents and young adults (age range 14-24 years at baseline) in the Munich area (Germany). The overall design of the study is prospective (average 42 months), consisting of a baseline survey (T0, $n=3021)$, three follow-up surveys (of which only the first two were used in the current paper-T1 and T2) and a family supplement. Fourteen- to 15-yearolds were sampled at twice the rate of persons 16-21 years of age, and 22- to 24-year-olds were sampled at half this rate. Because the primary goal of the study was to examine the incidence of psychopathology, the young group with the presumed highest incidence density was included at twice the rate and the oldest group at half the rate. A complete and detailed description of design, sample, instruments, procedures and statistical methods of the EDSP is given elsewhere (Wittchen et al. $1998 b)$.

The T0 sample was drawn in 1994 from the government registries in Munich, Germany, of registrants expected to be 14-24 years of age at the time of the T0 interview in 1995. Details about the sampling and representativeness of the whole EDSP sample, along with its sociodemographic characteristics, have been presented previously (Wittchen et al. 1998b; Lieb et al. 2000). A total of 3021 interviews were completed at T0 (response rate, $71 \%$ ). The first follow-up study (T1) was conducted only for respondents aged 14-17 years at T0, whereas the second follow-up study (T2) was conducted for all respondents. Of the 3021 respondents of the T0 study, a total of 2548 interviews were completed at $\mathrm{T} 2$, which occurred at an average of 42 months after T0 (response rate $84 \%$ ).

For the current report, the risk set consisted of all respondents with valid data at $\mathrm{T} 0$ and $\mathrm{T} 2$, on average 42 months later.

\section{Instruments}

\section{NEMESIS}

Subjects were interviewed at home by using the Composite International Diagnostic Interview (CIDI), version 1.1 (Smeets \& Dingemans, $1993)$, at T0 $(n=7076), \mathrm{T} 1 \quad(n=5618)$ and T2 $(n=4848)$. The CIDI is a structured interview developed by the World Health Organization (WHO), and generates diagnoses pertaining to DSM-III-R (APA, 1994). It was designed for use by trained interviewers who are not clinicians. Interviewers read the questions and recorded the answers of respondents, making the CIDI essentially a self-report instrument (Eaton et al. 2000). At T0, the lifetime version of the CIDI was used. At each of the follow-up assessments, the CIDI interval version was applied, which refers to the period of assessment from the last interview until the present. Data on the CIDI-G-section about psychosis were collected at each assessment (T0, T1, T2). At T0 and T2, telephone clinical reinterviews were held with individuals endorsing psychotic experiences as reported previously, to correct false-positive reports (Van Os et al. 2001; Hanssen et al. 2005). At T1, no clinical reinterviews were held, but interviewers were allowed to probe with clinical follow-up questions if individuals endorsed psychotic experiences and discussed these items later with a psychiatrist.

\section{EDSP}

Subjects were assessed with the computerassisted version of the Munich-CIDI (DIA-X/ M-CIDI; Wittchen \& Pfister, 1997), an updated version of the WHO CIDI version 1.2 (WHO, 1990). Diagnostic findings, according to the explicit diagnostic criteria of DSM-IV (APA, 1994), were obtained by using the M-CIDI diagnostic algorithms. Most interviews were carried out in the homes of the respondents. The M-CIDI is designed for use by trained interviewers who are not clinicians and has high inter-rater reliability and high test-retest reliability (Wittchen, 1994; Wittchen et al. 1998a). The assessment of psychotic disorders with CIDI by lay interviewers is not considered reliable (Anthony et al. 1985). Therefore, in the EDSP, trained psychologists who were allowed to probe with follow-up clinical questions conducted the interviews. At T0, the lifetime 
version of the M-CIDI was used. At each of the follow-up assessments, the M-CIDI interval version was applied, which refers to the period of assessment from the last interview until the present.

Data on the M-CIDI-G-section about psychosis were only collected at T2, at which time lifetime ratings of psychotic experiences were made without diagnostic differentiation, yielding cumulative incidence data up to the respective age of the respondents at $\mathrm{T} 2$.

At T0, and again at T2, participants also completed the self-report Symptom Checklist90-R (SCL-90-R) to screen for a broad range of psychological problems and symptoms of psychopathology. The SCL-90-R measures nine primary symptom dimensions and is designed to provide an overview of patients' symptoms and their severity (i.e. symptoms are scored dimensionally on a severity scale from 0 to 4 ) in the past 2 weeks. The reliability and validity of the SCL-90-R have been established previously (Bonicatto et al. 1997; Derogatis, 1977).

\section{Assessment of T0 psychotic experiences NEMESIS}

The CIDI psychosis section (G-section) was used to measure psychotic experiences at T0. This section consists of 17 psychosis items concerning delusions (13 items) and hallucinations (four items): items G1-G13, G15, G16, G20 and G21. Each item is scored on a scale of 1-6: 1, no symptom; 2, psychotic symptom present but not clinically relevant (not bothered by it and not seeking help for it); 3 , symptom is always the result of substance use; 4, symptom is always the result of somatic disorders or conditions; 5, true psychotic symptom; 6, interviewer is in doubt because there appears to be some plausible explanation for what appears to be a psychotic symptom. 'Baseline psychotic experiences' was defined as any CIDI rating of $2,3,4,5$ or 6 on any of the T0 17 CIDI core psychosis items.

\section{EDSP}

The SCL-90-R subscales 'Psychoticism' and 'Paranoia' were used to measure liability for psychosis at T0. These scales include self-reports on thought interference, hallucinations and suspiciousness, and can be regarded, if not as clear-cut psychotic symptoms, as a subclinical expression of psychotic experiences (items 7, 8, $16,18,35,43,62,68,76,77,83-85,87,88,90)$. The T0 'Psychoticism' and 'Paranoia' scales were combined into one psychosis scale by adding their scores and dividing the sum by two as described previously (Henquet et al. 2005). For the purpose of the analyses, 'baseline psychotic experiences' was a priori defined dichotomously as the group of individuals with the highest $10 \%$ of scores as described previously (Henquet et al. 2005).

\section{Assessment of psychosis outcome}

\section{NEMESIS}

The ratings from the 17 CIDI core psychosis items on delusions (13 items) and hallucinations (four items) were used to assess the presence of psychotic experiences (items G1-G13, G15, G16, G20, G21). 'Follow-up psychotic experiences' in this study was defined as any CIDI rating of $2,3,4,5$ or 6 on any of the 17 CIDI psychosis items at T1 or T2.

\section{EDSP}

The ratings at $\mathrm{T} 2$ from the $15 \mathrm{M}$-CIDI core psychosis items on delusions (11 items) and hallucinations (four items) were used to assess the presence of psychotic experiences (items G3-G5, G7-G14, G17, G18, G20, G21) in the sample. All psychosis items could be rated in two ways: 0 (no) and 1 (yes). Onset of psychotic experiences was recorded as within the last year or before that time. 'Follow-up psychotic experiences' in EDSP was defined as at least one positive rating on any of the $15 \mathrm{M}$-CIDI core psychosis items.

\section{Assessment of exposure variables \\ Cannabis exposure \\ NEMESIS}

Consistent with previous work (Van Os et al. 2002), the L-section of CIDI assesses use of cannabis. Cannabis exposure at T0 was defined as any lifetime cannabis use.

\section{EDSP}

Consistent with previous work (Henquet et al. 2005), the L-section of the M-CIDI assesses use of cannabis. Cannabis exposure at T0 was defined as lifetime cannabis use of five times or more. 
Trauma

\section{NEMESIS}

At T0, subjects were asked, using a semi-structured interview, whether they had experienced any kind of emotional, physical, psychological or sexual abuse before age 16 years, providing an example of each type of trauma. Subjects answered 'yes' or 'no' to each of the questions and were asked to give an indication about the frequency on a six-point scale: 1 , never; 2 , once; 3 , sometimes; 4 , regular; 5 , often; 6 , very often. Consistent with previous work (Janssen et al. 2004; Bak et al. 2005), in the analyses, experience of trauma was a priori dichotomized as follows: 'no early trauma' if the score on any item was $\leqslant 3$ and 'early trauma' if the score on any item was $>3$.

\section{EDSP}

Self-reported lifetime exposure to trauma was measured in the entire sample using the Posttraumatic stress disorder (PTSD) and Trauma module from the CIDI at T0 (Spauwen et al. 2006 b). This module started with trauma screening questions in which respondents could indicate a positive response on a visually presented list of nine groups of specified traumatic events such as 'experienced physical threat', 'experienced serious accident' or 'being sexually abused as a child'. A category of 'any traumatic event' indicated exposure to any of the nine traumata. The visual presentation of the list allowed respondents and interviewers to avoid speaking about sometimes embarrassing and stigmatizing traumata by simply indicating the number of the event. Consistent with previous work, affirmative responses to any of the events were labelled 'self-reported trauma' (Spauwen et al. 2006 b).

\section{Urbanicity exposure}

\section{NEMESIS}

Consistent with previous work, the original five-level classification of the urbanization measure expressed as density of addresses per $\mathrm{km}^{2}$ (Van Os et al. 2001, 2003) was dichotomized as follows: levels $1(<500), 2$ (500-900) and 3 (1000-1499) were coded as 0 and levels 4 $(1500-2499)$ and $5(\geqslant 2500)$ as 1 .

\section{EDSP}

Consistent with previous analyses (Spauwen et al. 2004, 2006a), urbanicity was defined as the
German city of Munich versus the surrounding areas of Munich. The population density of the surrounding areas was 553 persons per square mile and that of the city was 4061 persons per square mile.

\section{Statistical analyses}

All standard errors and tests statistics were estimated using the software package STATA, version 9.1 (StataCorp, 2005).

The dependent variable in the analyses was follow-up psychotic experiences, with environmental risk factors and baseline psychotic experiences as the independent variables. The risk of persistence of baseline psychotic experiences was defined as the strength of the association between baseline psychotic experiences and follow-up experiences. If the association between baseline psychotic experiences and follow-up psychotic experiences is significantly different for different levels of an environmental exposure (i.e. there is statistical interaction between baseline psychotic experiences and an environmental exposure), there is support for the hypothesis that this environmental exposure affects the persistence of baseline psychotic experiences.

For the analyses, the variable 'environmental load' was created. Environmental load was categorized into four levels: level 0, corresponding to no exposure (neither cannabis nor trauma nor urbanicity); level 1, corresponding to only one of the three exposures (cannabis or trauma or urbanicity); level 2, corresponding to two of the three exposures (cannabis and trauma or cannabis and urbanicity or trauma and urbanicity); and level 3, corresponding to all exposures (cannabis, trauma and urbanicity).

In line with recent advances in the conceptualization of interaction, we calculated the statistical additive interaction and estimated from that the population amount of synergism between baseline psychotic experiences and environmental load (Darroch, 1997; Van Os et al. 2002; Van Os \& Sham, 2003). This was done using the calculations developed by Darroch (1997) (see Appendix). For these analyses, a dichotomized measure of environmental load was used (levels 0 and 1 were coded 0 and levels 2 and 3 were coded 1; hereafter: high environmental load). For all other analyses, including the statistical additive interaction, the four-level continuous Environmental 
Load measure was used. To calculate the statistical interaction under an additive model, the BINREG procedure in STATA software (StataCorp, 2005) was used, which fits generalized linear models for the binomial family estimating risk differences (risk difference regression). Main effects were thus expressed on the additive scale (i.e. as a risk difference rather than a risk ratio). Estimates for risk differences were a priori adjusted for age, sex, educational level and any T0 CIDI lifetime DSM-III-R diagnosis. Interactions between environmental load and baseline psychotic experiences were fitted in the risk set of both NEMESIS and EDSP with environmental load entered both as a linear variable and as dummy variables with category 0 as the reference category, allowing estimation of baseline psychotic experiences effect sizes for each level of environmental load separately by calculating the appropriate linear combinations using the STATA LINCOM routine.

\section{Risk set}

\section{NEMESIS}

All the analyses were conducted in the group of individuals who had completed the CIDI psychosis G-section at T0 (7075 of 7076 subjects, $99.9 \%$ ), whose cannabis, trauma and urban exposures were documented $(n=7055)$ and who had completed the CIDI psychosis G-section at T1 and T2 $(n=4792)$, yielding a risk set of 4786 .

\section{EDSP}

All the analyses were conducted in the group of individuals who had completed the SCL-90-R subscales 'Psychoticism' and 'Paranoia' at T0 (3013 of 3021 subjects, $99.7 \%$ ), whose cannabis, trauma and urban exposures at T0 were documented $(n=2926)$ and who had completed the M-CIDI psychosis G-section at T2, yielding a risk set of 2452 .

\section{Sensitivity analysis}

In accordance with previous work conducted in the EDSP study sample (Spauwen et al. 2003, 2004), a sensitivity analysis was used in the EDSP risk set, to ensure that current findings relate only to prediction of incident psychotic experiences assessed with the M-CIDI. Thus, subjects who had reported psychotic experiences according to the M-CIDI at follow-up with onset longer than 1 year ago were excluded from the sensitivity analysis, thus ensuring that psychotic experiences reported at follow-up were not the same as those reported at baseline.

\section{RESULTS \\ Subjects}

In the risk set of 4786 subjects in the NEMESIS cohort, subjects were older than the 2452 subjects in the risk set of the EDSP cohort. Other differences related to demographic and instrument differences are depicted in Table 1. Of the 768 individuals with baseline psychotic experiences in NEMESIS, follow-up psychotic experiences were present in $200(26 \%)$. Of the 229 individuals with baseline psychotic experiences in EDSP, follow-up psychotic experiences were present in $71(31 \%)$.

\section{Synergism between baseline psychotic experiences and environmental load \\ NEMESIS}

The rate of follow-up psychotic experiences in the eight exposure levels defined by baseline psychotic experiences and environmental load are depicted in Table 2. For each level of exposure, the risk of having follow-up psychotic experiences was higher in subjects with baseline psychotic experiences than in the subjects without baseline psychotic experiences. The risk differences, i.e. the difference between the risk of having follow-up psychotic experiences in the groups with and without baseline psychotic experiences, separately for each level of environmental load, revealed that the association with follow-up psychotic experiences became progressively stronger as the level of environmental load went up. The risk difference effect size increased from $18 \cdot 2 \%$ for unexposed subjects (environmental load ' 0 '), to $33.9 \%$ for subjects exposed to all environmental factors (environmental load ' 3 '). These differences in effect size were significant, as evidenced by a significant positive interaction between environmental load and baseline psychotic experiences (Wald $\left.\chi^{2}=6.9, \quad \mathrm{df}=1, \quad p=0.009\right)$. This interaction changed only minimally after adjustment for age, sex, educational level and any T0 diagnosis (Wald $\chi^{2}=6 \cdot 6, \mathrm{df}=1, p=0 \cdot 01$ ).

The risk of follow-up psychotic experiences, in the group with neither baseline psychotic 
Table 1. Characteristics of subjects at TO, T0 exposure, baseline psychotic experiences and follow-up psychotic experiences, the Netherlands Mental Health Survey and Incidence Study (NEMESIS) and the Early Developmental Stages of Psychopathology study (EDSP)

\begin{tabular}{|c|c|c|c|c|}
\hline & \multicolumn{2}{|c|}{ NEMESIS $(n=4786)$} & \multicolumn{2}{|c|}{$\operatorname{EDSP}(n=2452)$} \\
\hline & $n$ & $\%$ & $n$ & $\%$ \\
\hline \multicolumn{5}{|l|}{ T0 } \\
\hline Age (years) & $41 \cdot 02$ & $11.9(18-64)$ & $18 \cdot 3$ & $3 \cdot 3(13-25)$ \\
\hline \multicolumn{5}{|l|}{ Gender } \\
\hline Male & 2227 & $46 \cdot 5$ & 1256 & $51 \cdot 2$ \\
\hline Female & 2559 & $53 \cdot 5$ & 1196 & $48 \cdot 8$ \\
\hline \multicolumn{5}{|c|}{ Level of education ${ }^{\mathrm{a}}$} \\
\hline 1 & 1434 & $30 \cdot 3$ & 298 & $12 \cdot 2$ \\
\hline 2 & 1752 & $37 \cdot 1$ & 738 & $30 \cdot 1$ \\
\hline 3 & 363 & $7 \cdot 7$ & 1416 & $57 \cdot 8$ \\
\hline 4 & 1178 & $24 \cdot 9$ & N.A. & N.A. \\
\hline \multicolumn{5}{|c|}{ Any T0 DSM diagnosis ${ }^{\mathrm{b}}$} \\
\hline No & 2880 & $60 \cdot 2$ & 1361 & $55 \cdot 5$ \\
\hline Yes & 1906 & $39 \cdot 8$ & 1091 & $44 \cdot 5$ \\
\hline \multicolumn{5}{|l|}{ Exposure status } \\
\hline \multicolumn{5}{|c|}{ Baseline psychotic experiences ${ }^{\mathrm{c}}$} \\
\hline No & 4018 & 83.9 & 2223 & $90 \cdot 7$ \\
\hline Yes & 768 & $16 \cdot 1$ & 229 & $9 \cdot 3$ \\
\hline \multicolumn{5}{|l|}{ Cannabis } \\
\hline No use & 4341 & $90 \cdot 7$ & 2131 & $86 \cdot 8$ \\
\hline Any use & 445 & $9 \cdot 3$ & 321 & $13 \cdot 2$ \\
\hline \multicolumn{5}{|l|}{ Trauma } \\
\hline Non-exposed & 4157 & $86 \cdot 9$ & 1970 & $80 \cdot 3$ \\
\hline Exposed & 629 & $13 \cdot 1$ & 482 & $19 \cdot 7$ \\
\hline \multicolumn{5}{|l|}{ Urbanization } \\
\hline Rural & 2998 & $62 \cdot 4$ & 728 & $29 \cdot 7$ \\
\hline Urban & 1798 & $37 \cdot 5$ & 1724 & $70 \cdot 3$ \\
\hline \multicolumn{5}{|c|}{ Environmental load ${ }^{\mathrm{d}}$} \\
\hline Zero & 2482 & $51 \cdot 9$ & 539 & $22 \cdot 0$ \\
\hline One & 1785 & $37 \cdot 5$ & 1386 & $56 \cdot 5$ \\
\hline Two & 450 & $9 \cdot 4$ & 440 & $17 \cdot 9$ \\
\hline Three & 59 & $1 \cdot 2$ & 87 & $3 \cdot 6$ \\
\hline \multicolumn{5}{|l|}{ T2 } \\
\hline \multicolumn{5}{|c|}{ Follow-up psychotic experiences ${ }^{\mathrm{e}}$} \\
\hline No & 4472 & $93 \cdot 4$ & 2026 & $82 \cdot 6$ \\
\hline Yes & 314 & 6.6 & 426 & $17 \cdot 4$ \\
\hline
\end{tabular}

N.A., Not applicable.

a NEMESIS: 1 = primary, basic vocational, $2=$ lower secondary, $3=$ higher secondary, $4=$ higher professional university. EDSP: $1=$ low, $2=$ medium, $3=$ high .

b NEMESIS: T0 any DSM-III-R diagnosis. EDSP: T0 any DSM-IV diagnosis.

NEMESIS: any Composite International Diagnostic Interview (CIDI) rating of 2, 3, 4, 5 or 6 on any of the T0 17 CIDI core psychosis items. EDSP: defined dichotomously as the group of individuals with the highest $10 \%$ of Symptom Checklist-90-R (SCL-90-R) scores.

d Zero = no exposure; one $=$ subjects exposed to only one of the three exposures; two=subjects exposed to two of the three exposures; three $=$ subjects exposed to all exposures.

e NEMESIS: any CIDI rating of 2, 3, 4, 5 or 6 on any of the 17 CIDI psychosis items at T1 or T2. EDSP: at least one positive rating on any of the $15 \mathrm{M}$-CIDI core psychosis items at T2.

experiences nor high environmental load (the dichotomized measure of environmental load as defined in Method section) was 2.6\% (95 of 3688 ). For the group exposed to high environmental load alone, this was $5.8 \%$ (19 of 330), $23.6 \%(139 / 589)$ for those exposed to baseline psychotic experiences alone, rising to $34 \cdot 1 \%$ $(61 / 179)$ in those exposed to both baseline psychotic experiences and high environmental load. Following the procedure developed by Darroch (1997) (see also formulas and tables in the Appendix), the proportion of individuals with follow-up psychotic experiences at T2 exposed to both baseline psychotic experiences and high environmental load that was attributable to the synergistic action of these factors 
Table 2. Interaction between baseline psychotic experiences and environmental load on the additive scale (risk difference), the Netherlands Mental Health survey and Incidence Study (NEMESIS)

\begin{tabular}{|c|c|c|c|c|c|c|c|}
\hline $\begin{array}{l}\text { Environmental } \\
\text { load }^{\mathrm{a}}\end{array}$ & $\begin{array}{c}\text { Baseline } \\
\text { psychotic } \\
\text { experiences }^{b}\end{array}$ & $\begin{array}{c}\text { With } \\
\text { follow-up } \\
\text { psychotic } \\
\text { experiences } \\
\quad(n)\end{array}$ & $\begin{array}{l}\text { Without } \\
\text { follow-up } \\
\text { psychotic } \\
\text { experiences } \\
\quad(n)\end{array}$ & $\begin{array}{l}\text { Risk of } \\
\text { having } \\
\text { follow-up } \\
\text { psychotic } \\
\text { experiences } \\
(\%)\end{array}$ & $\begin{array}{c}\text { Risk } \\
\text { difference } \\
(\%)\end{array}$ & $95 \% \mathrm{CI}$ & $p$ \\
\hline Zero & $\begin{array}{l}\text { No } \\
\text { Yes }\end{array}$ & $\begin{array}{l}43 \\
56\end{array}$ & $\begin{array}{r}2161 \\
222\end{array}$ & $\begin{array}{r}1 \cdot 9 \\
20 \cdot 1\end{array}$ & $18 \cdot 2$ & $13 \cdot 4-22 \cdot 9$ & $0 \cdot 000$ \\
\hline One & $\begin{array}{l}\text { No } \\
\text { Yes }\end{array}$ & $\begin{array}{l}52 \\
83\end{array}$ & $\begin{array}{r}1432 \\
228\end{array}$ & $\begin{array}{r}3 \cdot 5 \\
26 \cdot 7\end{array}$ & $23 \cdot 1$ & $18 \cdot 2-28 \cdot 1$ & $0 \cdot 000$ \\
\hline Two & $\begin{array}{l}\text { No } \\
\text { Yes }\end{array}$ & $\begin{array}{l}14 \\
47\end{array}$ & $\begin{array}{l}285 \\
104\end{array}$ & $\begin{array}{r}4 \cdot 7 \\
31 \cdot 1\end{array}$ & $26 \cdot 4$ & $18 \cdot 6-34 \cdot 2$ & $0 \cdot 000$ \\
\hline Three & $\begin{array}{l}\text { No } \\
\text { Yes }\end{array}$ & $\begin{array}{r}5 \\
14\end{array}$ & $\begin{array}{l}26 \\
14\end{array}$ & $\begin{array}{l}16 \cdot 1 \\
50 \cdot 0\end{array}$ & $33 \cdot 9$ & $11 \cdot 3-56 \cdot 5$ & $0 \cdot 003$ \\
\hline Additive interaction $^{\mathrm{d}}$ & & & & & $\chi^{2}=6.9$ & $\mathrm{df}=1$ & $0 \cdot 004$ \\
\hline
\end{tabular}

CI, Confidence interval; df, degrees of freedom.

a Zero=no exposure; one = subjects exposed to only one of the three exposures; two =subjects exposed to two of the three exposures; three $=$ subjects exposed to all exposures.

b Any Composite International Diagnostic Interview (CIDI) rating of 2, 3, 4, 5 or 6 on any of the T0 17 CIDI core psychosis items.

c Any CIDI rating of 2, 3, 4, 5 or 6 on any of the 17 CIDI psychosis items at T1 or T2.

Test for significant difference in increase in risk with one unit change in exposure rating between group with and without psychotic experiences.

was calculated. This calculation yielded figures for synergism between 0.073 and 0.283 , representing respectively $21 \%$ and $83 \%$ of the psychosis risk in those exposed to both baseline psychotic experiences and high environmental load $(0 \cdot 073 / 0 \cdot 341=21 \%$ and $0 \cdot 283 / 0 \cdot 341=$ $83 \%$ ). In other words, an estimated $21-83 \%$ of the individuals exposed at baseline to both baseline psychotic experiences and at least two of the environmental risk factors under examination had persistence of psychotic experiences at follow-up because of the synergistic action of the two factors.

\section{EDSP}

The rates of follow-up psychotic experiences in the eight exposures states are depicted in Table 3 . The risk difference effect size increased from $8 \cdot 3 \%$ for unexposed subjects, to $37.9 \%$ for subjects exposed to all three environmental risk factors. Again a significant positive interaction was evident between environmental load and baseline psychotic experiences (Wald $\chi^{2}=4 \cdot 2$, $\mathrm{df}=1, p=0.04)$. This interaction was not reduced after adjustment for age, sex, educational level and any $\mathrm{T} 0$ diagnosis (Wald $\chi^{2}=5 \cdot 3, \mathrm{df}=1$, $p=0.02)$. In the sensitivity analysis, the results similarly did not change after the exclusion of subjects presenting with an onset of psychotic experiences, according to the M-CIDI, more than 1 year ago (Wald $\chi^{2}=4 \cdot 2, \mathrm{df}=1, p=0 \cdot 04$ ). The risk of follow-up psychotic experiences was $14.8 \%$ in subjects exposed to neither baseline psychotic experiences nor high environmental load, $24.5 \%$ in those exposed to high environmental load alone, $20.7 \%$ in those exposed to baseline psychotic experiences alone, and $42.7 \%$ for those exposed to both baseline psychotic experiences and high environmental load. Filling in these risks in the formulas by Darroch (1997) revealed that between $29 \%$ and $51 \%$ of the individuals exposed to both baseline psychotic experiences and high environmental load had persistence of baseline psychotic experiences because of the synergistic action of these two factors.

\section{DISCUSSION}

To our knowledge, this is the first study that examined and replicated possible synergism between continuous developmental environmental load and psychotic experiences in predicting the minority of individuals who will display persistence of psychosis experiences. The two analyses presented replicated the finding 
Table 3. Interaction between psychotic experiences and environmental load on the additive scale (risk difference), the Early Developmental Stages of Psychopathology study (EDSP)

\begin{tabular}{|c|c|c|c|c|c|c|c|}
\hline $\begin{array}{l}\text { Environmental } \\
\text { load }^{\mathrm{a}}\end{array}$ & $\begin{array}{c}\text { Baseline } \\
\text { psychotic } \\
\text { experiences }\end{array}$ & $\begin{array}{c}\text { With } \\
\text { follow-up } \\
\text { psychotic } \\
\text { experiences } \\
\text { (n) }\end{array}$ & $\begin{array}{l}\text { Without } \\
\text { follow-up } \\
\text { psychotic } \\
\text { experiences } \\
\quad(n)\end{array}$ & $\begin{array}{l}\text { Risk of } \\
\text { having } \\
\text { follow-up } \\
\text { psychotic } \\
\text { experiences } \\
(\%)\end{array}$ & $\begin{array}{c}\text { Risk } \\
\text { difference } \\
(\%)\end{array}$ & $95 \% \mathrm{CI}$ & $p$ \\
\hline Zero & $\begin{array}{l}\text { No } \\
\text { Yes }\end{array}$ & $\begin{array}{l}66 \\
10\end{array}$ & $\begin{array}{r}427 \\
36\end{array}$ & $\begin{array}{l}13 \cdot 4 \\
21 \cdot 7\end{array}$ & $8 \cdot 3$ & $-3 \cdot 9$ to $20 \cdot 6$ & $0 \cdot 2$ \\
\hline One & $\begin{array}{l}\text { No } \\
\text { Yes }\end{array}$ & $\begin{array}{r}197 \\
26\end{array}$ & $\begin{array}{r}1088 \\
75\end{array}$ & $\begin{array}{l}15 \cdot 3 \\
25 \cdot 7\end{array}$ & $10 \cdot 4$ & $1 \cdot 7$ to $19 \cdot 2$ & $0 \cdot 02$ \\
\hline Two & $\begin{array}{l}\text { No } \\
\text { Yes }\end{array}$ & $\begin{array}{l}76 \\
24\end{array}$ & $\begin{array}{r}300 \\
40\end{array}$ & $\begin{array}{l}20 \cdot 2 \\
37 \cdot 5\end{array}$ & $17 \cdot 3$ & $4 \cdot 7$ to $29 \cdot 8$ & $0 \cdot 007$ \\
\hline Three & $\begin{array}{l}\text { No } \\
\text { Yes }\end{array}$ & $\begin{array}{l}16 \\
11\end{array}$ & $\begin{array}{r}53 \\
7\end{array}$ & $\begin{array}{l}23 \cdot 2 \\
61 \cdot 1\end{array}$ & $37 \cdot 9$ & $13 \cdot 3$ to $62 \cdot 5$ & $0 \cdot 003$ \\
\hline Additive interaction ${ }^{\mathrm{d}}$ & & & & & $\chi^{2}=4 \cdot 2$ & $\mathrm{df}=1$ & $0 \cdot 04$ \\
\hline
\end{tabular}

CI, Confidence interval; df, degrees of freedom.

a Zero = no exposure; one = subjects exposed to only one of the three exposures; two =subjects exposed to two of the three exposures; three $=$ subjects exposed to at all exposures.

b Defined dichotomously as the group of individuals with the highest $10 \%$ of Symptom Checklist-90-R (SCL-90-R) scores.

c At least one positive rating on any of the 15 Munich-Composite International Diagnostic Interview (M-CIDI) core psychosis items at T2

d Test for significant difference in increase in risk with one unit change in exposure rating between group with and without psychotic experiences.

that the probability of persistence of psychotic experiences was substantially greater in subjects exposed to all three environmental exposures compared to those with a lesser degree of exposure. Between $21 \%$ and $83 \%$ (NEMESIS), and $29 \%$ and $51 \%$ (EDSP), of the subjects exposed to both environmental exposures and psychotic experiences at T0 had persistence of expression of psychosis at follow-up because of the synergistic action of the two causes. These findings suggest that (i) the effect of different environmental risk factors for psychosis is additive, and (ii) if the environmental load were reduced, the prognosis of developmental expression of psychosis in the general population could be modified considerably, assuming causality.

In accordance with previous studies that examined associations with each environmental factor separately (cannabis use, trauma and urbanicity) (Van Os et al. 2002; Spauwen et al. 2004, 2006a, b; Van Os, 2004; Henquet et al. $2005)$, this triad of exposures may impact on risk for psychotic disorder by causing an abnormal persistence of a developmentally common expression of psychotic experiences, reflecting a plausible mechanism by which these risk factors may increase the risk for psychotic disorder. In addition, the environmental risk factors act additively in increasing the risk for persistence of psychotic experiences; the separate associations with each risk factor become a joint strong effect (Van Os et al. 2005b). Thus, under the influence of these three environmental factors, the first phase of the onset of psychotic disorder may be construed as the abnormal persistence and deterioration of a distributed developmental expression of psychosis.

\section{Analytical models of persistence of psychosis}

The central question of the analysis was persistence of psychotic experiences from baseline to follow-up. Analytically, this was tested using an interaction between baseline psychotic experiences and environmental load in the model of follow-up psychotic experiences. This model, however, assumes that environmental load does not increase the risk of baseline psychotic experiences (i.e. the variables making up the interaction are independent). If environmental load increases the risk for baseline psychotic experiences, the analysis cannot distinguish between a model of environmental load causing poor prognosis of prevalent psychotic experiences, and a model of environmental load causing incident poor prognosis psychotic experiences. In practice, however, the distinction between these two is academic, and in fact for 
most environmental exposure in psychiatry both mechanisms are likely to be true (Van Os et al. 2005a). Thus, a post-hoc analysis revealed that high environmental load was associated with baseline psychotic experiences in both NEMESIS [odds ratio (OR) 1.95, $95 \%$ confidence interval (CI) 1.79-2.14, $p<0.01]$ and EDSP (OR 1·49, 95\% CI 1·25-1·78, $p<0 \cdot 01$ ). Similarly, several risk factors for psychosis are associated not only with incidence, but also with persistence (Van Os et al. 1997, 1998). Thus, cannabis is associated not only with onset, but also with poor prognosis of psychotic illness (Grech et al. 2005).

\section{Possible mechanism of risk}

A hypothesis of a causal mechanism may reside in the more direct and indirect effects of cannabis, trauma and urbanicity during development, on what has been called dopamine sensitization (Laruelle, 2000; Howes et al. 2004). Thus, cannabis may have a direct developmental impact on dopamine sensitization. The primary active constituent of cannabis is delta-9-tetrahydrocannabinol (THC), affecting in particular the cannabinoid $\mathrm{CB} 1$ receptor in the brain (Freund et al. 2003; Howlett et al. 2004). The use of cannabis activates the $\mathrm{CB} 1$ receptor with a net effect of increased dopamine release in the limbic system (Cheer et al. 2004). Studies conducted in rats and human have suggested that puberty and adolescence are vulnerable periods with regard to THC exposure (Arseneault et al. 2002; Schneider \& Koch, 2003; Henquet et al. 2005). Repeated exposure to cannabis may lead to prolonged changes in the functioning of the dopamine system, and eventually dopamine sensitization (Henquet et al. 2005). These changes may be more important for subjects with a pre-existing vulnerability to dysregulation of the cannabinoid and related neurotransmitter systems (Caspi et al. 2005; Dean \& Murray, 2005; Henquet et al. 2005, 2006).

Recent studies have reported that neurotoxicity may be on the pathway between childhood trauma and schizophrenia supporting the traumatogenic neurodevelopmental (TN) model (Walker \& Diforio, 1997). In this model, childhood trauma may lead to neurodevelopmental abnormalities and particularly produce permanent damage in the stress regulation mechanism in the hypothalamic-pituitary-adrenal (HPA) axis (Bremner, 2005). The persistence of exposition to stressors and the chronicity of heightened glucocorticoid release, can induce permanent changes in the HPA axis and, through this, affect the dopamine system (Walker \& Diforio, 1997). Thus, exposure to stressors increases both cortisol release and dopamine, the latter being known as a neurotransmitter associated with the expression of psychosis (Kapur, 2003). It has been suggested that dopamine plays an important role by mediating the 'salience' of environmental events and internal representations (Berridge \& Robinson, 1998; Waelti et al. 2001). Schizophrenia may be associated with endogenous dopamine sensitization, a state characterized by hyper-responsiveness of dopamine neurons to environmental stimuli, in which even exposure to moderate levels of stress is associated with excessive dopamine (Lieberman et al. 1990; Duncan et al. 1999; Laruelle \& Abi-Dargham, 1999; Laruelle et al. 1999). Thus, a dysregulated, hyperdopaminergic state may lead to stimulus-independent dopamine release, which may take over the normal process of contextually driven salience attribution and then lead to aberrant assignment of salience to external objects and internal representations during the acute phase of psychosis (Kapur, 2003). In line with this, studies have reported that dopamine mediates the expression of psychotic experiences in patients with schizophrenia (Marcelis et al. 2004; Myin-Germeys et al. $2005 a, b)$.

The mechanism of behavioural or neurochemical sensitization may be involved in a comparable way for the developmental exposure referred to as 'urbanicity', reflecting in all likelihood an environmental exposure in urban environments. Growing up in an urban environment may increase the risk for people to be exposed to environmental stresses such as violence and victimization, social isolation and pollution rather than selection (Marcelis et al. 1998; Verheij et al. 1998; Pedersen \& Mortensen, 2001). Stressful environments might also give rise to behavioural sensitization as a reflection of dopamine sensitization (Myin-Germeys et al. $2005 a, b)$.

Thus, cumulative exposure to these additively acting developmental environmental risk factors in subjects with liability for psychosis, as 
evidenced by psychotic experiences may result in cumulative changes in the functioning of the dopamine system, possibly affecting the persistence and deterioration of developmental psychotic features.

\section{Methodological issues \\ Persistence of psychotic experiences and transition to psychotic disorder}

In the NEMESIS and EDSP datasets, the psychotic experiences at follow-up were assessed respectively with the CIDI and the M-CIDI, which are very close conceptually and logistically. Psychotic experiences are much more prevalent than psychotic disorders and the question arises as to what degree they reflect the same underlying phenotype. Research suggests that psychotic experiences reflect the lower end of a continuum, with more severe states such as schizophrenia at the highest end (Kendler et al. 1993; Chapman et al. 1994; Poulton et al. 2000; Van Os et al. 2000, 2001; Johns \& Van Os, 2001). Previous studies have shown that the environmental and genetic risk factors for schizophrenia, including the environmental risk factors examined in this study, have an impact on the occurrence of both clinical psychotic disorder and subclinical psychotic experiences (Verdoux et al. 1998; Johns \& Van Os, 2001; Van Os \& Jones, 2001; Van Os et al. 2001, 2002; Krabbendam et al. 2002; Spauwen et al. 2003; Janssen et al. 2004; Henquet et al. 2005). As transition from a subclinical state to a clinical disorder necessarily involves a degree of persistence and subsequent deterioration, our findings suggest that exposure to the three environmental risk factors influences not only the persistence of psychotic experiences but also, through this, the emergence of psychotic disorder. However, further research is needed to examine whether and how persistence of psychotic experience leads to the development of need for care and a diagnosable disorder.

\section{Baseline psychotic experiences at T0}

The SCL-90-R was used to measure psychotic experiences at T0 in EDSP. The fact that this instrument covers only the past 2 weeks may have led to an underestimation of the true positives at T0. Nevertheless, the repercussions of this misclassification would only be a decrease in risk differences between groups, and is thus unlikely to result in spurious findings. The validity of the measure of psychotic experiences by a self-report instrument may be questionable. However, a recent study demonstrated the validity of the assessment of psychotic experiences by self-report in a general population sample (Konings et al. 2006), and the longitudinal validity of self-reported psychotic experiences in population samples has also been established (Poulton et al. 2000; Hanssen et al. 2005).

\section{Psychotic experiences at T2}

The CIDI and M-CIDI were used in the NEMESIS and EDSP studies respectively to measure psychotic experiences at follow-up. The limitation of the CIDI is that this instrument is not considered reliable to assess psychotic disorders by lay interviewers (Anthony et al. 1985). However, subjects were assessed by faceto-face interview, which may have yielded better results than a self-report questionnaire. In addition, clinical reinterviews were conducted in both NEMESIS and EDSP, the psychologists who conducted the interviews were allowed to probe with follow-up questions, thus making the interview clinical rather than self-report (Spauwen et al. 2006 b).

\section{APPENDIX}

Estimation of the amount of biological synergism between baseline psychotic experiences and environmental load (see Darroch, 1997; Van Os et al. 2002; Van Os \& Sham, 2003)

To quantify the extent to which (proxy) genetic risk and environmental factors act synergistically in disease causation, we have to consider the population that has developed psychosis after exposure to both (proxy) genetic and environmental risk factors, taking into account the possibility that among those subjects some of them would have developed psychosis after the exposure to either (proxy) genetic risk or environmental risk alone, which refers to parallelism (Darroch, 1997; Van Os et al. 2002; Van Os \& Sham, 2003). If there is parallelism (proxy) genetic and environmental risks are competitive in causing psychosis. Thus, if the proportion of subjects that develops psychosis because the 
co-participation of (proxy) genetic risk and environmental risk decreases, there is more competition between both risk factors. It is not possible to calculate the amount of synergy and the amount of parallelism in subjects exposed to both (proxy) genetic liability and environmental exposure. However, the estimation of the amount of biological synergism can be approximated, in part, from the calculation of which synergism exceeds parallelism (Darroch, 1997; Van Os et al. 2002; Van Os \& Sham, 2003).

To calculate this excess of synergism, we use the risk effects associated with the four exposure states. For illustration, the table of risk effects for subjects from the NEMESIS study is constructed:

\begin{tabular}{l|cc}
\hline \multicolumn{1}{c}{} & \multicolumn{2}{c}{$\begin{array}{c}\text { (proxy) Genetic risk } \\
\text { Psychotic experiences }\end{array}$} \\
\cline { 2 - 3 } & + & - \\
\hline $\begin{array}{l}\text { Environmental } \\
\text { risk }\end{array}$ & $+\mathrm{R}(\mathrm{GE})-\mathrm{R}=0.341$ & $\mathrm{R}(\mathrm{E})-\mathrm{R}=0.236$ \\
$\begin{array}{l}\text { Environmental } \\
\text { load }\end{array}$ & $-\mathrm{R}(\mathrm{G})-\mathrm{R}=0.058$ & $\mathrm{R}=0.026$ \\
\hline
\end{tabular}

The risk of having follow-up psychotic experiences in the group exposed to neither psychotic experiences nor more than one environmental exposure was 2.6\% (95/3688). The risks in those only exposed to psychotic experiences and no or one environmental risk factor was $5 \cdot 8 \%(19 / 330)$, in those exposed to environmental exposures alone $23.6 \%$ (139/ $589)$, and the risk in those exposed to both factors $34 \cdot 1 \%(61 / 179)$.

The excess of the combined effects of (proxy) genetic and environmental risk over the sum of their solitary effects is the effect associated with the combined exposure to (proxy) genetic and environmental risk minus the effect associated with the exposure to (proxy) genetic risk alone and minus the effect associated with environmental risk alone. The amount by which synergism exceeds parallelism equals the excess of the combined effect of (proxy) genetic risk and environmental risk over the sum of the solitary effects of (proxy) genetic risk and environmental risk, which is the statistical additive interaction (Darroch, 1997; Van Os et al. 2002; Van Os \& Sham, 2003).
$[\mathrm{R}(\mathrm{GE})-\mathrm{R}(\mathrm{G})-\mathrm{R}(\mathrm{E})+\mathrm{R}]=\mid$ synergism $\mid$

$-\mid$ parallelism $\mid=$ statistical additive interaction.

If synergism is positive, then the statistical additive interaction is positive, if synergism is equal to zero, the statistical additive interaction is inferior or equal to zero.

For example, filling in the risks of the NEMESIS study in the previous formula:

$$
\begin{aligned}
& {[\mathrm{R}(\mathrm{GE})-\mathrm{R}(\mathrm{G})-\mathrm{R}(\mathrm{E})+\mathrm{R}]} \\
& \quad=0.341-0.058-0.236+0 \cdot 026=0 \cdot 073
\end{aligned}
$$

The statistical additive interaction is positive $(0.073)$, indicating that baseline psychotic experiences and environmental load interact on the additive scale.

The next step is to fill these risks in, in the following table (Darroch, 1997):

\begin{tabular}{ll|c} 
Synergism $\mid$ & $\times 2$ & $\begin{array}{r}\mathrm{R}(\mathrm{GE})-\mathrm{R}(\mathrm{G}) \\
=0.341-0.058 \\
=0.283\end{array}$ \\
$\times 1$ & |Parallelism| & $\begin{array}{r}\mathrm{R}(\mathrm{G})-\mathrm{R} \\
=0.058-0.026 \\
=0.032\end{array}$ \\
& & \\
$\begin{array}{ll}\mathrm{R}(\mathrm{GE})-\mathrm{R}(\mathrm{E}) & \mathrm{R}(\mathrm{E})-\mathrm{R} \\
=0.341-0.236 & =0.236-0.026 \\
=0.105 & =0.21\end{array}$
\end{tabular}

Synergism was between $0 \cdot 073$ and $0 \cdot 283$, which represents respectively $21 \%$ and $83 \%$ of the psychosis risk in those exposed to both psychotic experiences and environmental load $(0 \cdot 073 / 0 \cdot 341=21 \%$ and $0 \cdot 283 / 0 \cdot 341=83 \%)$. Thus, an estimated $21 \%$ to $83 \%$ of subjects exposed to both exposures and baseline psychotic experiences had follow-up psychotic experiences because of the synergistic action of the two causes.

\section{ACKNOWLEDGEMENTS}

The NEMESIS was supported by the Dutch Department of Health. This work is also part of the EDSP study and was funded by the German Ministry of Research and Technology, project nos 01EB9405/6, 01EB 9901/6 and EB01016200. Part of the field work and analyses were also supported by grants from the Deutsche Forschungsgemeinschaft (DFG) LA1148/1-1 and WI2246/1-1. The principal investigators are Drs Hans-Ulrich Wittchen and Roselind Lieb. 
Core staff members of the EDSP group are: Dr Kirsten von Sydow, Dr Gabriele Lachner, Dr Axel Perkonigg, Dr Peter Schuster, Michael Höfler, Holger Sonntag, Tanja Brückl, Elzbieta Garczynski, Dr Barbara Isensee, Agnes Nocon, Dr Chris Nelson, Hildegard Pfister, Dr Victoria Reed, Barbara Spiegel, Andrea Schreier, Dr Ursula Wunderlich and Dr Petra Zimmermann. Scientific advisors are: Dr Jules Angst (Zurich), Dr Jürgen Margraf (Basel), Dr Günther Esser (Potsdam), Dr Kathleen Merikangas (NIMH, Bethesda), Dr Ron Kessler (Harvard, Boston) and Dr Jim Van Os (Maastricht).

\section{DECLARATION OF INTEREST}

None.

\section{REFERENCES}

Anthony, J. C., Folstein, M., Romanoski, A. J., Von Korff, M. R., Nestadt, G. R., Chahal, R., Merchant, A., Brown, C. H., Shapiro, S., Kramer, M. \& Gruenberg, E. M. (1985). Comparison of the lay Diagnostic Interview Schedule and a standardized psychiatric diagnosis. Experience in eastern Baltimore. Archives of General Psychiatry 42, 667-675.

APA (1994). Diagnostic Criteria from the DSM-IV. American Psychiatric Press: Washington, DC

Arseneault, L., Cannon, M., Poulton, R., Murray, R., Caspi, A. \& Moffitt, T. E. (2002). Cannabis use in adolescence and risk for adult psychosis: longitudinal prospective study. British Medical Journal 325, 1212-1213

Bak, M., Krabbendam, L., Janssen, I., de Graaf, R., Vollebergh, W. \& van Os, J. (2005). Early trauma may increase the risk for psychotic experiences by impacting on emotional response and perception of control. Acta Psychiatrica Scandinavica 112, 360366.

Berridge, K. C. \& Robinson, T. E. (1998). What is the role of dopamine in reward: hedonic impact, reward learning, or incentive salience? Brain Research. Brain Research Reviews 28, 309-369.

Bijl, R. V., Ravelli, A. \& van Zessen, G. (1998a). Prevalence of psychiatric disorder in the general population: results of the Netherlands Mental Health Survey and Incidence Study (NEMESIS). Social Psychiatry and Psychiatric Epidemiology 33, 587-595.

Bijl, R. V., van Zessen, G., Ravelli, A., de Rijk, C. \& Langendoen, Y. $(1998 b)$. The Netherlands Mental Health Survey and Incidence Study (NEMESIS): objectives and design. Social Psychiatry and Psychiatric Epidemiology 33, 581-586.

Bonicatto, S., Dew, M. A., Soria, J. J. \& Seghezzo, M. E. (1997) Validity and reliability of Symptom Checklist '90 (SCL90) in an Argentine population sample. Social Psychiatry and Psychiatric Epidemiology 32, 332-338.

Bremner, J. D. (2005). Effects of traumatic stress on brain structure and function: relevance to early responses to trauma. Journal of Trauma and Dissociation 6, 51-68.

Caspi, A., Moffitt, T. E., Cannon, M., McClay, J., Murray, R., Harrington, H., Taylor, A., Arseneault, L., Williams, B., Braithwaite, A., Poulton, R. \& Craig, I. W. (2005). Moderation of the effect of adolescent-onset cannabis use on adult psychosis by a functional polymorphism in the catechol-O-methyltransferase gene: longitudinal evidence of a gene $\times$ environment interaction. Biological Psychiatry 57, 1117-1127.
Chapman, L. J., Chapman, J. P., Kwapil, T. R., Eckblad, M. \& Zinser, M. C. (1994). Putatively psychosis-prone subjects 10 years later. Journal of Abnormal Psychology 103, 171-183.

Cheer, J. F., Wassum, K. M., Heien, M. L., Phillips, P. E. \& Wightman, R. M. (2004). Cannabinoids enhance subsecond dopamine release in the nucleus accumbens of awake rats. Journal of Neuroscience 24, 4393-4400.

Cunningham Owens, D. G. \& Johnstone, E. C. (2006). Precursors and prodromata of schizophrenia: findings from the Edinburgh High Risk Study and their literature context. Psychological Medicine 36, 1501-1514.

Darroch, J. (1997). Biologic synergism and parallelism. American Journal of Epidemiology 145, 661-668.

de Graaf, R., Bijl, R. V., Smit, F., Ravelli, A. \& Vollebergh, W. A. (2000). Psychiatric and sociodemographic predictors of attrition in a longitudinal study: The Netherlands Mental Health Survey and Incidence Study (NEMESIS). American Journal of Epidemiology 152, 1039-1047.

Dean, K. \& Murray, R. M. (2005). Environmental risk factors for psychosis. Dialogues in Clinical Neuroscience 7, 69-80.

Derogatis, L. R. (1977). The SCL-90 Manual: Scoring Administration and Procedures for the SCL-90. Johns Hopkins University School of Medicine, Clinical Psychometrics Unit: Baltimore.

Duncan, G. E., Sheitman, B. B. \& Lieberman, J. A. (1999). An integrated view of pathophysiological models of schizophrenia. Brain Research. Brain Research Reviews 29, 250-264.

Eaton, W. W., Neufeld, K., Chen, L. S. \& Cai, G. (2000). A comparison of self-report and clinical diagnostic interviews for depression: diagnostic interview schedule and schedules for clinical assessment in neuropsychiatry in the Baltimore epidemiologic catchment area follow-up. Archives of General Psychiatry 57, 217-222.

Freund, T. F., Katona, I. \& Piomelli, D. (2003). Role of endogenous cannabinoids in synaptic signaling. Physiological Reviews 83 1017-1066.

Grech, A., Van Os, J., Jones, P. B., Lewis, S. W. \& Murray, R. M. (2005). Cannabis use and outcome of recent onset psychosis. European Psychiatry 20, 349-353.

Hanssen, M., Bak, M., Bijl, R., Vollebergh, W. \& van Os, J. (2005). The incidence and outcome of subclinical psychotic experiences in the general population. British Journal of Clinical Psychology 44, 181-191.

Hanssen, M., Krabbendam, L., Vollema, M., Delespaul, P. \& Van Os, J. (2006). Evidence for instrument and family-specific variation of subclinical psychosis dimensions in the general population. Journal of Abnormal Psychology 115, 5-14.

Henquet, C., Krabbendam, L., Spauwen, J., Kaplan, C., Lieb, R., Wittchen, H. U. \& van Os, J. (2005). Prospective cohort study of cannabis use, predisposition for psychosis, and psychotic symptoms in young people. British Medical Journal 330, 11.

Henquet, C., Rosa, A., Krabbendam, L., Papiol, S., Fananas, L.,Drukker, M., Ramaekers, J. G. \& van Os, J. (2006). An experimental study of catechol-O-methyltransferase Val(158)Met moderation of delta-9-tetrahydrocannabinol-induced effects on psychosis and cognition. Neuropsychopharmacology 31, 27482757.

Howes, O. D., McDonald, C., Cannon, M., Arseneault, L., Boydell, J. \& Murray, R. M. (2004). Pathways to schizophrenia: the impact of environmental factors. International Journal of Neuropsychopharmacology 7 (Suppl. 1), S7-S13.

Howlett, A. C., Breivogel, C.S., Childers, S. R., Deadwyler, S. A., Hampson, R. E. \& Porrino, L. J. (2004). Cannabinoid physiology and pharmacology: 30 years of progress. Neuropharmacology $\mathbf{4 7}$ (Suppl. 1), 345-358.

Janssen, I., Krabbendam, L., Bak, M., Hanssen, M., Vollebergh, W. de Graaf, R. \& van Os, J. (2004). Childhood abuse as a risk factor for psychotic experiences. Acta Psychiatrica Scandinavica 109 $38-45$.

Johns, L. C. \& Van Os, J. (2001). The continuity of psychotic experiences in the general population. Clinical Psychology Review 21, 1125-1141. 
Kapur, S. (2003). Psychosis as a state of aberrant salience: a framework linking biology, phenomenology, and pharmacology in schizophrenia. American Journal of Psychiatry 160, 13-23.

Kendler, K. S., McGuire, M., Gruenberg, A. M., O'Hare, A. Spellman, M. \& Walsh, D. (1993). The Roscommon Family Study. III. Schizophrenia-related personality disorders in relatives. Archives of General Psychiatry 50, 781-788.

Konings, M., Bak, M., Hanssen, M., van Os, J. \& Krabbendam, L. (2006). Validity and reliability of the CAPE: a self-report instrument for the measurement of psychotic experiences in the general population. Acta Psychiatrica Scandinavica 114, 55-61.

Krabbendam, L., Janssen, I, Bak, M., Bijl, R. V., de Graaf, R. \& van Os, J. (2002). Neuroticism and low self-esteem as risk factor for psychosis. Social Psychiatry and Psychiatric Epidemiology 37, $1-6$

Laruelle, M. (2000). The role of endogenous sensitization in the pathophysiology of schizophrenia: implications from recent brain imaging studies. Brain Research. Brain Research Reviews 31, 371-384.

Laruelle, M. \& Abi-Dargham, A. (1999). Dopamine as the wind of the psychotic fire: new evidence from brain imaging studies. Journal of Psychopharmacology 13, 358-371.

Laruelle, M., Abi-Dargham, A., Gil, R., Kegeles, L. \& Innis, R. (1999). Increased dopamine transmission in schizophrenia: relationship to illness phases. Biological Psychiatry 46, 56-72.

Lieb, R., Isensee, B., von Sydow, K. \& Wittchen, H. U. (2000) The Early Developmental Stages of Psychopathology Stud (EDSP): a methodological update. European Addiction Research 6, $170-182$.

Lieberman, J. A., Kinon, B. J. \& Loebel, A. D. (1990). Dopaminergic mechanisms in idiopathic and drug-induced psychoses. Schizophrenia Bulletin 16, 97-110.

Linney, Y. M., Murray, R. M., Peters, E. R., MacDonald, A. M., Rijsdijk, F. \& Sham, P. C. (2003). A quantitative genetic analysis of schizotypal personality traits Psychological Medicine 33, 803-816.

Marcelis, M., Cavalier, E., Gielen, J., Delespaul, P. \& Van Os, J. (2004). Abnormal response to metabolic stress in schizophrenia: marker of vulnerability or acquired sensitization? Psychological Medicine 34, 1103-1111.

Marcelis, M., Navarro-Mateu, F., Murray, R., Selten, J. P. \& Van Os, J. (1998). Urbanization and psychosis: a study of 1942-1978 birth cohorts in the Netherlands. Psychological Medicine 28 871-879.

Myin-Germeys, I., Delespaul, P. \& van Os, J. (2005a). Behavioural sensitization to daily life stress in psychosis. Psychological Medicine 35, 733-741.

Myin-Germeys, I., Krabbendam, L. \& van Os, J. (2003). Continuity of psychotic symptoms in the community. Current Opinion in Psychiatry 16, 443-449.

Myin-Germeys, I., Marcelis, M., Krabbendam, L., Delespaul, P. \& van Os, J. (2005b). Subtle fluctuations in psychotic phenomena as functional states of abnormal dopamine reactivity in individuals at risk. Biological Psychiatry 58, 105-110.

Pedersen, C. B. \& Mortensen, P. B. (2001). Family history, place and season of birth as risk factors for schizophrenia in Denmark: a replication and reanalysis. British Journal of Psychiatry 179, 46-52.

Peters, E. R., Joseph, S. A. \& Garety, P. A. (1999). Measurement of delusional ideation in the normal population: introducing the PDI (Peters et al. Delusions Inventory). Schizophrenia Bulletin 25, 553-576.

Poulton, R., Caspi, A., Moffitt, T. E., Cannon, M., Murray, R. \& Harrington, H. (2000). Children's self-reported psychotic symptoms and adult schizophreniform disorder: a 15-year longitudinal study. Archives of General Psychiatry 57, 1053-1058.

Schneider, M. \& Koch, M. (2003). Chronic pubertal, but not adult chronic cannabinoid treatment impairs sensorimotor gating, recognition memory, and the performance in a progressive ratio task in adult rats. Neuropsychopharmacology 28, 1760-1769.
Smeets, R. M. W. \& Dingemans, P. M. A. J. (1993). Composite International Diagnostic Interview (CIDI) Version 1.1. World Health Organization: Geneva.

Spauwen, J., Krabbendam, L., Lieb, R., Wittchen, H. U. \& van Os, J. (2003). Sex differences in psychosis: normal or pathological? Schizophrenia Research 62, 45-49.

Spauwen, J., Krabbendam, L., Lieb, R., Wittchen, H. U. \& van Os, J. (2004). Does urbanicity shift the population expression of psychosis? Journal of Psychiatric Research 38, 613-618.

Spauwen, J., Krabbendam, L., Lieb, R., Wittchen, H. U. \& van Os, J. $(2006 a)$. Evidence that the outcome of developmental expression of psychosis is worse for adolescents growing up in an urban environment. Psychological Medicine 36, 407-415.

Spauwen, J., Krabbendam, L., Lieb, R., Wittchen, H. U. \& van Os, J. $(2006 \mathrm{~b})$. Impact of psychological trauma on the development of psychotic symptoms: relationship with psychosis proneness. British Journal of Psychiatry 188, 527-533.

StataCorp (2005). STATA Statistical Software: Release 9.0. Stata Corporation, College Station: TX, USA.

Van Os, J. (2004). Does the urban environment cause psychosis? British Journal of Psychiatry 184, 287-288.

Van Os, J., Bak, M., Hanssen, M., Bijl, R. V., de Graaf, R. \& Verdoux, H. (2002). Cannabis use and psychosis: a longitudinal population-based study. American Journal of Epidemiology 156 319-327.

Van Os, J., Hanssen, M., Bak, M., Bijl, R. V. \& Vollebergh, W. (2003). Do urbanicity and familial liability coparticipate in causing psychosis? American Journal of Psychiatry 160, 477-482.

Van Os, J., Hanssen, M., Bijl, R.-V. \& Ravelli, A. (2000). Straus (1969) revisited: a psychosis continuum in the general population? Schizophrenia Research 45, 11-20.

Van Os, J., Hanssen, M., Bijl, R. V. \& Vollebergh, W. (2001) Prevalence of psychotic disorder and community level of psychotic symptoms: an urban-rural comparison. Archives of General Psychiatry 58, 663-668.

Van Os, J., Henquet, C. \& Stefanis, N. (2005a). Cannabis-related psychosis and the gene-environment interaction: comments on Ferdinand et al. 2005. Addiction 100, 874-875

Van Os, J. \& Jones, P. B. (2001). Neuroticism as a risk factor for schizophrenia. Psychological Medicine 31, 1129-1134.

Van Os, J., Jones, P., Sham, P., Bebbington, P. \& Murray, R. M. (1998). Risk factors for onset and persistence of psychosis. Social Psychiatry and Psychiatric Epidemiology 33, 596-605.

Van Os, J., Krabbendam, L., Myin-Germeys, I. \& Delespaul, P. $(2005 b)$. The schizophrenia envirome. Current Opinion in Psychiatry 18, 141-145.

Van Os, J., Pedersen, C. B. \& Mortensen, P. B. (2004). Confirmation of synergy between urbanicity and familial liability in the causation of psychosis. American Journal of Psychiatry 161, $2312-2314$

Van Os, J. \& Sham, P. (2003). Gene-environment interactions. In The Epidemiology of Schizophrenia (ed. R. M. Murray, P. B. Jones, E. Susser, J. Van Os and M. Cannon), pp. 235-254 Cambridge University Press: Cambridge.

Van Os, J., Wright, P. \& Murray, R. M. (1997). Risk factors for emergence and persistence of psychosis. In Progress in Clinical Psychiatry (ed. M. Weller and D. Van Kammen), pp. 152-206. W. B. Saunders Company Ltd: London.

Verdoux, H., Van Os, J., Maurice-Tison, S., Gay, B., Salamon, R. \& Bourgeois, M. (1998). Is early adulthood a critical developmental stage for psychosis proneness? A survey of delusional ideation in normal subjects. Schizophrenia Research 29 $247-254$.

Verheij, R. A., van de Mheen, H. D., de Bakker, D. H., Groenewegen, P. P. \& Mackenbach, J. P. (1998). Urban-rural variations in health in The Netherlands: does selective migration play a part? Journal of Epidemiology and Community Health $\mathbf{5 2}$ 487-493.

Waelti, P., Dickinson, A. \& Schultz, W. (2001). Dopamine responses comply with basic assumptions of formal learning theory. Nature 412, 43-48. 
Walker, E. F. \& Diforio, D. (1997). Schizophrenia : a neural diathesisstress model. Psychological Review 104, 667-685.

Wittchen, H. U. (1994). Reliability and validity studies of the WHOComposite International Diagnostic Interview (CIDI): a critica review. Journal of Psychiatric Research 28, 57-84.

Wittchen, H. U., Lachner, G., Wunderlich, U. \& Pfister, H.

$(1998 a)$. Test-retest reliability of the computerized DSM-IV version of the Munich-Composite International Diagnostic Interview (M-CIDI). Social Psychiatry and Psychiatric Epidemiology 33, 568-578.

Wittchen, H. U, Perkonigg, A., Lachner, G, \& Nelson, C. B. (1998b). Early Developmental Stages of Psychopathology Study
(EDSP): objectives and design. European Addiction Research 4, $18-27$.

Wittchen, H. U. \& Pfister, H. (1997). DIA-X-Interviews: Manual für Screening-Verfahren und Interview; Interviewheft längsschnittuntersuchung (DIA-X-Lifetime); Ergänzungsheft (DIA-XLifetime); Interviewheft Querschnittsuntersuchung (DIA-X-12 Monats-Version); Ergänzungsheft (DIA-X-12 Monats-Version); PC-Programm zur Durchführung der Interviews (Länsund Ouerschnittsuntersuchung). Auswertungsprogramm. Swets and Zeitlinger: Frankfurt.

WHO (1990). Composite International Diagnostic Interview (CIDI), Version 1.0. World Health Organization: Geneva. 